\title{
The Cervical Spinal Canal Tapers Differently in Patients with Chiari I with and without Syringomyelia
}

\author{
(D)A. Thompson, (D) N. Madan, (D).R. Hesselink, (D). Weinstein, (D)A. Munoz del Rio, and (D). Haughton
}

\begin{abstract}
BACKGROUND AND PURPOSE: The cause of syringomyelia in patients with Chiari I remains uncertain. Cervical spine anatomy modifies CSF velocities, flow patterns, and pressure gradients, which may affect the spinal cord. We tested the hypothesis that cervical spinal anatomy differs between Chiari I patients with and without syringomyelia.

MATERIALS AND METHODS: We identified consecutive patients with Chiari I at 3 institutions and divided them into groups with and without syringomyelia. Five readers measured anteroposterior cervical spinal diameters, tonsillar herniation, and syrinx dimensions on cervical MR images. Taper ratios for $\mathrm{Cl}-\mathrm{C} 7, \mathrm{Cl}-\mathrm{C} 4$, and $\mathrm{C4}-\mathrm{C7}$ spinal segments were calculated by linear least squares fitting to the appropriate spinal canal diameters. Mean taper ratios and tonsillar herniation for groups were compared and tested for statistical significance with a Kruskal-Wallis test. Inter- and intrareader agreement and correlations in the data were measured.

RESULTS: One hundred fifty patients were included, of which 49 had syringomyelia. Cl-C7 taper ratios were smaller and C4-C7 taper ratios greater for patients with syringomyelia than for those without it. $\mathrm{Cl}-\mathrm{C} 4$ taper ratios did not differ significantly between groups. Patients with syringomyelia had, on average, greater tonsillar herniation than those without a syrinx. However, C4-C7 taper ratios were steeper, for all degrees of tonsil herniation, in patients with syringomyelia. Differences among readers did not exceed differences among patient groups.
\end{abstract}

CONCLUSIONS: The tapering of the lower cervical spine may contribute to the development of syringomyelia in patients with Chiari I.

$\mathbf{P}^{2}$ atients with a Chiari I malformation frequently develop syringomyelia, in theory the result of CSF flow obstructed by ectopic cerebellar tonsils. Phase-contrast MR imaging studies of CSF flow in the foramen magnum support this theory. Oscillatory CSF fluid flow has greater velocities and greater complexity in patients with Chiari I than in healthy subjects. ${ }^{1}$ Why some patients with Chiari I develop syringomyelia and other do not has not yet been explained. How hyperdynamic CSF flow at the craniovertebral junction causes syringomyelia lower in the cervical spine has also not been elucidated.

Abnormal tonsil position is not a necessary or a sufficient cause for syringomyelia because not all patients with Chiari I have

Received August 9, 2015; accepted after revision September 15

From the Departments of Radiology (A.T., A.M.d.R., V.H.) and Medical Physics (A.M.d.R.), University of Wisconsin School of Medicine and Public Health, Madison, Wisconsin; Department of Radiology (N.M., G.W.), Tufts University School of Medicine, Boston, Massachusetts; and Department of Radiology (J.R.H.), University of California San Diego, San Diego, California.

Please address correspondence to Victor Haughton, MD, Department of Radiology, University of Wisconsin School of Medicine and Public Health, Madison, WI

53702; e-mail:vmhaughton@wisc.edu

http://dx.doi.org/10.3174/ajnr.A4597 syringomyelia and not all patients with syringomyelia have tonsillar herniation. The extent of tonsillar herniation does not predict the presence of syringomyelia. Therefore, factors other than tonsil herniation may have a role in the pathogenesis of syringomyelia. For example, one factor may be the size of the posterior cranial fossa; another pathogenetic factor may be the patency of the central canal within the cervical or thoracic spinal cord. ${ }^{2,3}$

The possibility that cervical spinal canal anatomy has a role in the pathogenesis of syringomyelia has not been extensively studied. The spinal canal narrows between $\mathrm{C} 1$ and $\mathrm{C} 4$ in healthy subjects ${ }^{4}$ and in patients with Chiari I. ${ }^{5}$ The tapering of the upper cervical spinal canal causes peak CSF velocities to increase from $\mathrm{C} 1$ to $\mathrm{C} 4 .{ }^{6,7}$ Taper ratios, the slope of a line fit to spinal canal diameters at multiple spinal levels, differ between patients with Chiari I and controls. ${ }^{5,8}$ We designed this study to test the hypothesis that Chiari I patients with syringomyelia have different cervical spinal canal taper ratios than Chiari I patients without syringomyelia.

\section{MATERIALS AND METHODS}

Approval for this retrospective study was obtained from the respective institutional review boards of the 3 sites: the University of Wisconsin School of Medicine and Public Health, Tufts University 
School of Medicine, and the University of California, San Diego School of Medicine. The requirement for written informed consent was waived. This study conformed to Health Insurance Portability and Accountability Act standards. We recruited 5 readers: A) a staff neuroradiologist at the University of Wisconsin School of Medicine and Public Health who was also a visiting scientist at the Tuft University Medical Center; B) a resident radiologist at the University of Wisconsin School of Medicine and Public Health; C) a staff neuroradiologist; D) a resident at Tufts University Medical Center; and E) a staff neuroradiologist at the University of California San Diego School of Medicine. Readers re-read a fraction of cases 1 or 2 times with at least 2 weeks between readings.

Cases of Chiari I were collected by reviewing the PACS between January 2012 and July 2013 for cervical spine MR imaging or in 1 institution by reviewing the Chiari I case registry. Inclusion criteria were any patient with sagittal T2-weighted fast spin-echo cervical spine images (at $1.5 \mathrm{~T}$ or $3 \mathrm{~T}$ ) who had $\geq 5$ - $\mathrm{mm}$ cerebellar tonsil herniation. Patients were excluded if they had a history or evidence of a Chiari II malformation, tumor, trauma, infection, prior spine surgery, or poor-quality images. Cervical and thoracic MR images were inspected for the presence of a fluid collection in the spinal cord consistent with a syrinx.

For each patient, the sagittal T2-weighted cervical spine MR imaging sequence was reviewed by using a DICOM image viewer to identify the midline section or sections that best showed the spinous processes or dens at each cervical level. Cerebellar tonsil herniation was measured by placing a line from the tip of the inferior end of the basion to the anterior rim of the opisthion and measuring the perpendicular distance from this line to the inferior tip of the cerebellar tonsils on the sagittal image that best demonstrated the tonsil. The anteroposterior diameter of the cervical spinal canal from $\mathrm{C} 1$ to $\mathrm{C} 7$ was measured on the midline sagittal T2 images by a previously described method. ${ }^{6,7}$ At each level, a line was placed perpendicular to the spinal axis at the midpoint of the vertebra, the points where it crossed from CSF to epidural tissue were identified, and the distances between them were measured. At C1, the midpoint of the anterior arch of $\mathrm{C} 1$ was defined, and the line was drawn transverse to the spinal axis at this level. We measured the foramen magnum anteroposterior dimensions at the site with the largest enrollment as in previous studies. The $\mathrm{C} 1-\mathrm{C} 7, \mathrm{C} 1-\mathrm{C} 4$, and $\mathrm{C} 4-\mathrm{C} 7$ taper ratios were calculated by least squares fitting of a line to the appropriate diameters, by using the LINE ST macro in Excel (Microsoft, Redmond, Washington) as in previous studies. ${ }^{6,7}$ The length of the syringomyelia was calculated as the number of segments over which it extended. The readers measured the maximal anteroposterior diameter of the syrinx on the midsagittal T2-weighted image.

\section{Analysis and Statistical Testing}

The diameter measurements for all readers were tabulated together with the patient age, sex, tonsillar herniation, syrinx location, and dimensions. Two sets of readings were created to control for the possibility of reader effects. The measurements of readers $\mathrm{B}, \mathrm{C}$, and $\mathrm{E}$ were pooled as set 1 , and the measurements of readers A (from 2 sites) and E were pooled as set 2. (Reader E's 9 readings, the only ones at the site, were included in both sets because there was only 1 reader at this site.) The mean taper ratios for the pa- tients with Chiari I with and without syringomyelia were calculated and tested for significance by the Kruskal-Wallis rank sum test, with significance set at .05. Tonsillar herniation was compared among groups with a Kruskal-Wallis test. The effect of age, sex, institution, and reader was tested on the pooled datasets with Kruskal-Wallis and Fisher exact tests for continuous and categoric responses, respectively. $P$ values were not adjusted for multiple testing. All statistical computations and graphics were obtained in R 3.1.0 (R Core Team 2014; http://www.r-project.org). We performed regression analysis with macros in Excel.

For reader-agreement analysis, 55 readings by reader $\mathrm{B}$ at site 1 were compared with readings in the same patients by reader $\mathrm{A}$, and 90 readings by reader $C$ at site 2 were compared with readings in the same patients by reader A. For intrareader agreement, reader B reread a subset of patients $(n=21)$ and reader A reread a subset of patients for a second $(n=20)$ and third time $(n=10)$, with a minimum of 2 weeks between readings.

Inter- and intrareader agreement was analyzed with BlandAltman 95\% limits of agreement. We calculated the bias and the typical discrepancy between 2 measurements, accounting for the clustering that results from combining multiple diameters from the same subject. ${ }^{9}$

\section{RESULTS}

The readers measured spinal canal diameters in 101 patients with Chiari I without and 49 with syringomyelia at the 3 institutions. Females comprised $66 \%$ and $67 \%$ of the patients in sets 1 and 2, respectively. Readers A, B, C, D, and E measured 146, 55, 90, 9 , and 89 cases, respectively. Sets 1 and 2 differed in the number of patients by 4 , due to omissions of cases in which a reader believed that measurements were inexact because of artifacts or other problems with the image.

On average, syringes were 5 vertebral segments in length (range, $1-13$ segments) and $0.36 \mathrm{~cm}$ in anteroposterior diameter (range, $0.1-1.67 \mathrm{~cm}$ ). Syringes terminated superiorly most frequently at the C6 level (13 cases) and at other levels between C1 and $\mathrm{T} 2$ in other cases.

$\mathrm{C} 1-\mathrm{C} 7$ and $\mathrm{C} 1-\mathrm{C} 4$ taper ratios had negative signs indicating narrower diameters at the caudal end; $\mathrm{C} 4-\mathrm{C} 7$ taper ratios had positive signs indicating larger diameters at their caudal ends (Fig 1 and Table). For C1-C7, taper ratios were $-0.057 \pm 0.034 \mathrm{~cm} /$ level (set 1 ) and $-0.052 \pm 0.033 \mathrm{~cm} /$ level (set 2) for patients with Chiari I without syrinx and $-0.036 \pm 0.041 \mathrm{~cm} /$ level (set 1 ) and $-0.032 \pm 0.039 \mathrm{~cm} /$ level (set 2) for the patients with syringomyelia. The difference was significant in both sets $(P=.003$ and .019 for sets 1 and 2, respectively).

The average foramen magnum diameters were $3.2 \mathrm{~cm}$ in $30 \mathrm{pa}-$ tients with and $3.1 \mathrm{~cm}$ in 53 patients without a syrinx; this difference was not significant $(P=.2)$. The diameters at $\mathrm{C} 1 \mathrm{for}$ the patients at the 3 sites were 1.7 and $1.6 \mathrm{~cm}$, respectively, in the cases with and without syrinx; this difference was also not significant $(P=.4)$.

$\mathrm{C} 1-\mathrm{C} 4$ taper ratios were $-0.147 \pm 0.072 \mathrm{~cm} /$ level (set 1 ) and $-0.129 \pm 0.070 \mathrm{~cm} /$ level (set 2) in patients with Chiari I without syringomyelia and $-0.122 \pm 0.086 \mathrm{~cm} /$ level (set 1 ) and $-0.115 \pm$ $0.078 \mathrm{~cm} /$ level (set 2) for the patients with Chiari I with syringomyelia (set 1 ). The difference was not statistically significant in either set ( $P=.08$ and .38 for sets 1 and 2 , respectively). 


\section{Taper ratios of the cervical spine in Chiari 1 patients with and without syringomyelia}

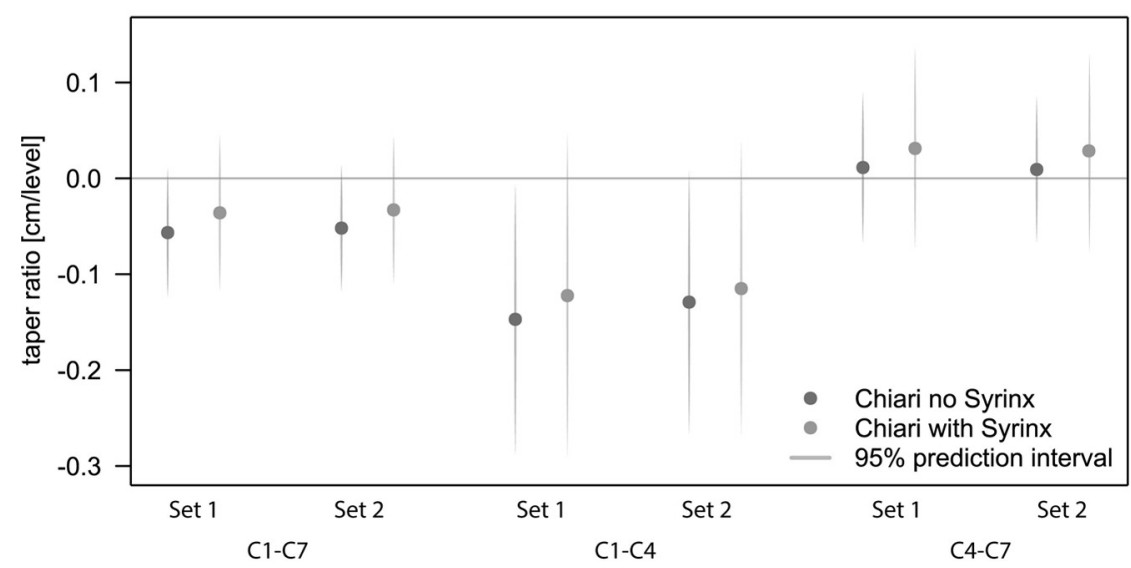

FIG 1. $\mathrm{Cl}-\mathrm{C} 7, \mathrm{Cl}-\mathrm{C} 4$, and $\mathrm{C} 4-\mathrm{C} 7$ taper ratios and $95 \%$ confidence intervals for set 1 and 2 readings in patients with Chiari I without and with syrinx.

Taper ratios for $\mathrm{Cl}-\mathrm{C7}, \mathrm{Cl}-\mathrm{C4}$, and $\mathrm{C4}-\mathrm{C7}$ and tonsillar ectopia in patients with Chiari I with and without a syrinx

\begin{tabular}{lccccc}
\hline & \multicolumn{2}{c}{ Reader Set 1 } & & \multicolumn{2}{c}{ Reader Set 2 } \\
\cline { 2 - 3 } \cline { 5 - 6 } \cline { 5 - 6 } & Without Syrinx & With Syrinx & & Without Syrinx & With Syrinx \\
\hline Cl-C7 Taper ratio (cm/level) & -0.057 & $-0.036^{\mathrm{a}}$ & & -0.052 & $-0.032^{\mathrm{a}}$ \\
C1-C4 Taper ratio (cm/level) & -0.147 & -0.122 & & -0.129 & -0.115 \\
C4-C7 Taper ratio (cm/level) & +0.011 & $+0.031^{\mathrm{a}}$ & & +0.009 & $+0.028^{\mathrm{a}}$ \\
Tonsillar ectopia $(\mathrm{mm})$ & 9.8 & $10.8^{\mathrm{a}}$ & & 12.0 & $12.7^{\mathrm{a}}$ \\
\hline
\end{tabular}

${ }^{a}$ Significant differences between cases with and without syrinx $(P<.05)$.
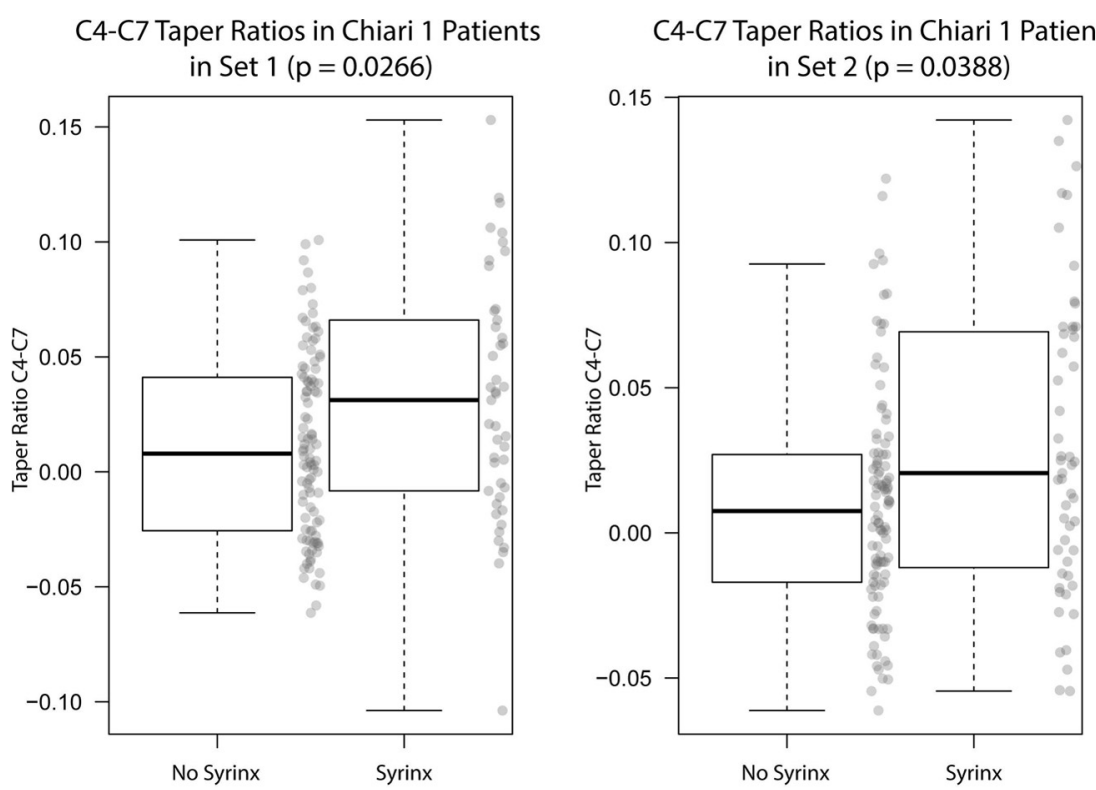

FIG 2. Box-and-whisker plot of the $\mathrm{C} 4-\mathrm{C} 7$ taper ratios in patients with Chiari I without and with a syrinx. For sets 1 and 2, taper ratios differed significantly between groups $(P=.026, .039)$.

C4-C7 taper ratios (Fig 2) were $0.011 \pm 0.040 \mathrm{~cm} /$ level (set 1) and $0.009 \pm 0.039 \mathrm{~cm} /$ level (set 2) for the patients without syringomyelia and $0.031 \pm 0.053 \mathrm{~cm} /$ level (set 1 ) and $0.028 \pm 0.052 \mathrm{~cm} /$ level (set 2) for patients with syringomyelia. The difference was significant in both sets ( $P=.027$ and .039 for sets 1 and 2, respectively).

Tonsillar descent averaged $9.82 \pm 3.98 \mathrm{~mm}$ (set 1$)$ and $10.8 \pm$ $4.79 \mathrm{~mm}$ (set 2) in the patients with Chiari I without syrinx and
$12.0 \pm 5.01 \mathrm{~mm}($ set 1$)$ and $12.7 \pm 5.43$ $\mathrm{mm}$ (set 2) in the patients with Chiari I with syringomyelia. The differences between the 2 groups were significant $(P=$ .008 and .020 for sets 1 and 2, respectively).

Regression analysis showed that the C4-C7 taper ratio was 0.001 (tonsil herniation $)+0.21$ for the Chiari cases without syringomyelia and 0.001 (tonsil herniation $)+0.42$ for the Chiari cases with syringomyelia. The taper ratio in patients with Chiari I with a syrinx was on average $0.021 \mathrm{~cm} /$ level greater than that in the group without syrinx for any degree of tonsillary herniation. The length of the syrinx correlated significantly with the $\mathrm{C} 4-\mathrm{C} 7$ taper ratio $(P=.02)$.

Because the proportion of females and the ages on average were similar in the 2 groups, sex and age were not confounding factors. The $\mathrm{C} 4-\mathrm{C} 7$ taper ratios were greater on average in males than in females by $0.02 \mathrm{~cm} /$ level $(P=$ .027 and .007 for sets 1 and 2, respectively). Sex had no significant effect on the position of the tonsils below the foramen magnum $(P=.77$ and .998 for sets 1 and 2, respectively). C1-C4 taper ratios tended to be larger with age $(P=$ .153 and .011 for sets 1 and 2, respectively) as did the $\mathrm{C} 1-\mathrm{C} 7$ taper ratios $(P=.23$ and .010 for sets 1 and 2 , respectively). The $\mathrm{C} 4-\mathrm{C} 7$ taper ratio was not affected by age $(P=.58$ and .933 for sets 1 and 2, respectively). No other statistically significant effects of age or sex were noted.

For 2 readers at site 1, the systematic difference (bias) between measurements by different readers in the same cases was $0.02 \mathrm{~mm}$, and the variability between the 2 readers was 0.16 to $-1.22 \mathrm{~mm}$ in $95 \%$ of cases. The systematic difference between the 2 measurements at site 2 was $0.01 \mathrm{~mm}$, and the variability between the 2 readings was 0.31 to $-0.33 \mathrm{~mm}$ in $95 \%$ of cases. For 1 reader at site 1 , the systematic difference between a first and second reading was $0.005 \mathrm{~mm}$ and the variability was 0.15 to $-0.13 \mathrm{~mm}$ in $95 \%$ of cases. Inter- and intrareader agreement was similar in all other comparisons.

\section{DISCUSSION}

The cervical spinal canal tapers differently in patients with Chiari I with syringomyelia compared with those without it. In both groups, the spinal canal narrows from C1 to C7. Patients with Chiari I with a 
syrinx have a steeper positive $\mathrm{C} 4-\mathrm{C} 7$ taper (wider caudally). The C4-C7 taper accounts for the differences in the C1-C7 segment because the $\mathrm{C} 1-\mathrm{C} 4$ taper does not differ significantly between the groups.

Patients with Chiari I with syringomyelia have, on average, greater tonsillar herniation than those without a syrinx. On average, patients with syringomyelia, regardless of the amount of tonsillar herniation, have a greater $\mathrm{C} 4-\mathrm{C} 7$ taper than patients without it.

Given the multicenter nature of the study and the need for multiple readers, the study was divided into 2 reader sets to assess the influence of reader effect. For virtually all of the measurements made, agreement was excellent among the readers.

In comparison with published studies, the patients in this study had similar morphologic features. Tonsil herniation in these patients compared well with the average of $11 \mathrm{~mm}$ reported previously in a cohort of patients with Chiari I, some of whom had syringomyelia. ${ }^{10}$ Syringomyelia most frequently extended superiorly to the level of C6 in this study, which is in keeping with previous reports. ${ }^{10}$ Taper ratios for $\mathrm{C} 1-\mathrm{C} 7, \mathrm{C} 1-\mathrm{C} 4$, and $\mathrm{C} 4-\mathrm{C} 7 \mathrm{in}$ patients with Chiari I with syringomyelia in this study $(-0.036$, -0.122 , and $0.031 \mathrm{~cm} /$ level, respectively) agree well with those previously reported ${ }^{11}$ in patients with distended syringes $(-0.034,-0.098$, and $0.024 \mathrm{~cm} /$ level, respectively). Our taper ratios does not agree well with $\mathrm{C} 1-\mathrm{T} 1$ taper ratios in a sample of 21 patients reported previously, ${ }^{5}$ perhaps because of issues of linear fitting to curving portions of the cervical spine, different patient ages, or smaller sample sizes in the previous report. In a previous report of 2 patients with scoliosis with and 20 without syrinx, the presence of a syrinx does not produce a significant difference in the $\mathrm{C} 1$ to $\mathrm{C} 7$ taper ratios. ${ }^{8}$ The small sample size may explain the difference from our results.

The study has limitations due to the inclusion of multiple readers and multiple medical institutions. The patients from the 3 institutions differed to some degree in age distributions and severity of syringomyelia, probably because of the types of services offered at each institution and the proportion of pediatric patients treated. Reader disagreements in diameter measurements resulted from different placement of the transverse line on which to measure the diameters and from imprecisely defining the junction of the subarachnoid space and the epidural tissues. The use of the taper ratio tended to moderate the effect of random measurement errors. Linear fitting to diameters better suits short and relatively straight spinal segments (C1-C4 and C4-C7) than the entire cervical spine, which may curve. Sex and age had an effect on taper ratios, but not on the differences between the 2 patient groups, because the proportion of females and the ages, on average, were similar in the 2 groups. Creating 2 sets of data increased confidence that results were not reader-dependent.

The results in this study do not accord with the common assumption that syringomyelia results predominantly from spinal obstruction at the level of the foramen magnum. However, because tonsillar ectopia and crowding at the foramen magnum do not accurately predict the development of syringomyelia, other factors may be suspected. Greater positive C4-C7 tapering (expansion) of the spine suggests decreasing rather than increasing CSF velocities below $\mathrm{C} 4$ in these patients. The juxtaposition of negatively and positively tapering cervical segments produces complex pressure gradients during the cardiac cycle, which may contribute to the pathogenesis of syringomyelia. Other anatomic features relevant to syringomyelia may include variations in the central canal within the spinal cord and posterior fossa morphology. ${ }^{2,11}$

The steeper C4-C7 taper ratios in patients with Chiari I with syringomyelia warrant additional study. One hypothesis to test is that the cervical spinal canal tapers differently in patients with idiopathic syringomyelia than in controls who lack a syrinx.

\section{CONCLUSIONS}

Cervical spinal canal tapering may be a morphologic factor contributing to the development of syringomyelia in some patients with Chiari I malformation. Computational fluid dynamics in anatomically accurate models of the cervical spine may help explain why some patients develop a syrinx.

Disclosures: Alejandro Munoz del Rio-RELATED: Grant: Column of Hope*; UNRELATED: Grants/Grants Pending: National Institutes of Health*; Other: Lippincott, Williams, and Wilkins, Comments: I provided statistical review for Annals of Surgery. Victor Haughton—RELATED: Grant: Column of Hope, ${ }^{\star}$ Comments: Funds for the statistician. *Money paid to the institution.

\section{REFERENCES}

1. Quigley MF, Iskandar BJ, Quigley MA, et al. Cerebrospinal fluid flow in foramen magnum: temporal and spatial patterns at MR imaging in volunteers and in patients with Chiari I malformation. Radiology 2004;232:229-36 CrossRef Medline

2. Drøsdal IN, Mardal KA, Støverud K, et al. Effect of the central canal in the spinal cord on fluid movement in the cord. Neuroradiol J2013; 26:585-90 Medline

3. Støverud KH, Alnæs M, Langtangen HP, et al. Poro-elastic modeling of syringomyelia: a systematic study of the effects of pia mater, central canal, median fissure, white and gray matter on pressure wave propagation and fluid movement within the cervical spinal cord. Comput Methods Biomech Biomed Engin 2016;19:686-98 CrossRef Medline

4. Tatarek NE. Variation in the human cervical neural canal. Spine J 2005;5:623-31 Medline

5. Hirano M, Haughton V, Munoz del Rio A. Tapering of the cervical spinal canal in patients with Chiari I malformations. AJNR Am J Neuroradiol 2012;33:1326-30 CrossRef Medline

6. Shah S, Haughton V, del Río AM. CSF flow through the upper cervical spinal canal in Chiari I malformation. AJNR Am J Neuroradiol 2011;32:1149-53 CrossRef Medline

7. Rutkowska G, Haughton V, Linge S, et al. Patient-specific 3D simulation of cyclic CSF flow at the craniocervical region. AJNR Am J Neuroradiol 2012;33:1756-62 CrossRef Medline

8. Hammersley J, Haughton V, Wang Y, et al. Tapering of the cervical spinal canal in patients with scoliosis with and without the Chiari I malformation. AJNR Am J Neuroradiol 2012;33:1752-55 CrossRef Medline

9. Bland JM, Altman, DG. Agreement between methods of measurement with multiple observations per individual. J Biopharm Stat 2007;17:571-82 CrossRef Medline

10. Elster AD, Chen MY. Chiari I malformations: clinical and radiologic reappraisal. Radiology 1992;183:347-53 CrossRef Medline

11. Zhu Z, Sha S, Sun X, et al. Tapering of the cervical spinal canal in patients with distended or nondistended syringes secondary to Chiari type I malformation. AJNR Am J Neuroradiol 2014;35: 2021-26 CrossRef Medline 